\title{
Who is Richard Parker? - An Analysis of the Tiger Character in Life of Pi
}

\author{
Yan-Yu ZHANG \\ Zhejiang University of Water Resources and Electric Power \\ Hangzhou, China 310018 \\ elainecheung@126.com
}

Key words: Life of Pi; Tiger; Mirror Image; Identity

\begin{abstract}
As the main leading role in the Booker Prize winner Life of Pi in 2002, the Bengal tiger named Richard Parker has gained great popularity and various analysis that comes along. Was Richard Parker a real tiger once in the life of Pi? If not, what was he? In this paper, with the help of Lacan's Mirror Image Theory, the analysis of the tiger starts from the existing doubts and by expounding the importance of his presence, the tiger's identity is to be verified and the reasons that Pi makes him become clear.
\end{abstract}

\section{Introduction}

As the Booker Prize winner in 2002, Yann Martel's second novel Life of Pi [1]tells us an amazing story about how a young boy called Pi drifted alone in the endless Pacific Ocean for 227 days in a small lifeboat yet with a fully-grown Bengal tiger named Richard Parker and finally survived.

There have been quite a lot of book reviews since the book was published. But most of the critics [2-4] focus on either the theme of the book or the truth of the story while ignoring the animal protagonist in it. Pamela Cooper once pointed out in her paper that "[i]n the novel, the marvelous body of the animal becomes both an image of God and a sign of the inexplicable cruelty of the world" [5] while Yann Martel himself had subtly kept the tiger out though he had explained why it's named Richard Parker in one of his articles [6].

Therefore, all the doubts and suspicions about the tiger still remain unanswered and unrevealed. As a result, the audience is still baffled in their comprehension of the novel:

Is Richard Parker a real tiger? If not, what is he?

Or rather, according to symbolism that Yann Martel had mentioned in his article:

Who is Richard Parker?

\section{Why Does a Tiger Appear on the Life Boat?}

According to what Mr. Adirubasamy has ever claimed in the beginning of the book (p.XIII), the tiger story can "make you believe in God". Meanwhile, Pi offered two diverse versions of his own drifting life and when the Japanese officials were asked to choose the better story, they picked out the first story with the tiger and Pi judged it as God's choice (p.424). Then there's the question: what makes the tiger story "the better story"? For the readers who feel uneasy to "believe in God", there is another question: if the story with the tiger is better, is Richard Parker a mere tiger? If not, what is he?

Yann Martel was once asked some similar questions in an interview [7]. In his answer, "believing in fiction" and "believing in God" were put together and "fiction" was equated with "God". Stewart Cole criticized it by reasoning that Yann Martel had mistaken the better story by acknowledging its aesthetic value and impact out of subjective choice as the belief in God and takes it as the objective truth [8], whereas Florence Stratton called it as "tiger aesthetic" [3] --- people choose the tiger story because it is expected "to provide a means of coping with trauma, to offer a defense against traumatic reality”. 
But it doesn't mean that people believe in its truth. Instead, suspicions never disappear in readers' mind when they read through the story: how could a man and a tiger live so peacefully in such a small boat for 227 days? Is it real?

\section{Is there a Real Tiger on the Boat?}

Pi's drifting life seems quite incredible to the audience as Pi himself admitted ("it's an incredible story” (p.397)) when they read through his story with a hungry mature Bengal tiger. However, the young boy's words seemed paradox --- he agreed with the Japanese investigators but also argued vehemently like a sophist (p.399-400).

The whole novel is divided into 100 chapters but readers are not told the real identity of the tiger until the 37th chapter by referring the animal as "he". In fact, most of the descriptions do not comply with the traits and characters as a tiger. Anthropomorphism can be found everywhere so that it is natural for readers to raise the question: is Richard Parker a real tiger?

There's little information about Richard Parker in Pi's Indian life with only one black-and-white photo left:

"That's Richard Parker," he says.

I'm amazed. I look closely, trying to extract personality from appearance. Unfortunately, it's black and white again and a little out of focus. ... Richard Parker is looking away. He doesn't even realize that his picture is being taken. (p.116)

The audience tends to mistake "him" as one of the school children if they don't know the real identity of Richard Parker in advance. With the word "personality", and with the illustration of the picture, it successfully brings about ambiguity and confusion. As William Empson said, no matter how slight it is, such ambiguity "gives room for alternative reactions to the same piece of language" ${ }^{[8]}$ though it is only Pi that can be able to appoint the photo tiger as Richard Parker and also can decide whether or not there was the tiger called Richard Parker in his Indian life (p.424).

What's more, while staying with Pi in their Pacific life, Richard Parker kept a tamed animal and “did not really want to attack me” (p.277-278) as Pi claimed: how could a sixteen-year-old boy, with training knowledge seemingly self-made, be so successful in taming the fiercest animal over the world? Not to say his lacking of training tools and the restriction of space --- with only a whistle and several pieces of fish, Pi met with success on the narrow deck of a "three and a half feet deep, eight feet wide and twenty-six feet long" (p.182) lifeboat. Pi's narrative "leaps into a fantasy realm that challenges the reader by its apparent departure from the predominantly realistic mode of the rest of the novel” [5].

\section{Who is Richard Parker?}

As a 16-year-old boy who had never been out of his hometown before, Pi was suddenly deserted as an orphan on a small lifeboat. He knew little about the marine environment. What would he do to survive in the endless Pacific Ocean?

In Jacques Lacan's theory [9], the Mirror Stage comes from an analogical situation. Before the moment that the subject came into the world, the infant used to enjoy a self-sufficient life in his mother's uterus. Yet when he was forced out of it, he had to be faced with a completely strange world which was not comfortable and well-fed any more.

Similarly, Pi was thrown onto a lifeboat in the Pacific Ocean alone in a rainstorm night with most of the people were still in their deep sleep (p.132-138). Pi described the sea as rough with wind and rain but when it ended, the weather improved quickly (p.422-423) and right after the ship sank it became a beautiful day. The whole process looks like an exaggerated course of giving birth to a baby.

In Lacan's theory, while being abruptly pitched (seprécipite) into this world unwittingly, the infant's body is still not fully developed to deal with the outside world. In the first early months, he would have a certain dehiscence at the heart of the organism and a primordial discord betrayed by the signs of uneasiness and motor uncordination. In his early boat days, Pi was confined to the 
lifeboat, facing numerous dangers and challenges - there's a tiger under tarpaulin and he never had a boat life all by himself. Inexperienced, powerless and incapable, Pi looks exactly like a newborn infant.

When the infant has turned from the passive acceptance phase to the active (though imaginary) behavior one, which is exemplified by the infant's gazing at his own reflection in the mirror, Lacan believes that imaging (the Imago theory in psychology as Lacan cites) means $s$ kind of identification, which plays a fatal role in human's growth and maturing period. It's a unique experience for humans because when the infant sees that the reflection in the mirror does accordingly when he acts, he tends to misrecognize as his free and smooth control over the mirror image. Based on the identification of imago, there's an acquirement of imaginary power of control for the infant. In this phase, the infant overcome this frustration for the first time when he was born.

In Pi's story, we can find that the boy annotates the theory very well with an interactive relationship with his boat companion Richard Parker, just as the one established between the baby and his own image that he discovers in the mirror. An evident annotation is that Pi and Richard Parker had their own territory and never had crossed the border. They both remained in their own world safe and sound, living a taming-and-being tamed life of co-existence.

Meanwhile, Pi narrated repeatedly of the tiger's gazing at him. When Richard Parker first pulled himself aboard the lifeboat, his eyes were "blazing" (p.130); after the tiger killed the hyena, he turned full round "till he was looking straight at" the boy: "when Richard Parker's amber eyes met mine, the stare was intense, cold and unflinching, not flighty or friendly, and spoke of self-possession on the point of exploding with rage" (p.201-202); Richard Parker "raised himself onto the gunnel and looked my way” (p.213); “[h]e was looking at me intently”, "simply taking me in, observing me, in a manner that was sober but not menacing" (p.216); "I sat up --- only to discover that I was dead centre in the focus of his stare" (p.241); "Richard Parker never stared back; his gaze always floated in mid-air, neither on me nor off me" (p.284); "[a]fter a few seconds he turned away too and our gazes briefly met" (p.317); "Richard Parker was observing me from the lifeboat” (p.350).

All these various gazes remind the audience of the infant's looking at his own reflection in the mirror. Moreover, Pi and Richard Parker mostly did the same things: eating food and sleeping the rest time. Except that, Pi would act as the food-supplier and tiger-trainer and both were just proofs to show that Pi was the master of Richard Parker, like what the infant would do with his mirror image.

Therefore, when Pi claimed that turning to God made him survive (p.417), we would rather believe that it was his mirror image which vested the imaginary power of control in him that successfully made the boy go through the harsh days at sea.

\section{Summary}

The imaginary control of the mirror image is actually void and therefore fails to take the place of the virtual activities of body control in the real life. Thus, the infant can only be attracted for a period of time and when he's about eighteen months old, the infant would start to turn from the reflection infatuation to the attempt of instrument control and contact with the other. Hence the end of the mirror stage.

Different from the infant, however, the young boy Pi had to interrupt his mirror stage when the boat finally reached the Mexican shore. It explains the reason why Pi never forgave Richard Parker for his "unceremonious" leave "without any sort of goodbye" (p.7): Richard Parker did not look at Pi when they landed at beach (p.382) as Pi wished. Instead, he "only looked fixedly into the jungle" and then disappeared in it.

The whole situation went beyond Pi's expectation because unlike the infant, he never did it out of initiative. Consequently, Pi never finished his mirror stage. In fact, he was always living in a state of self-fragmentation and identity confusion as we can tell from his Canadian life later on and his study on both cosmogony theory and the three-toed sloth (p.3-5): “[do] something to soothe [his] shattered self”. 


\section{References}

[1] Martel, Yann. Life of Pi, Toronto: Alfred A. Knopf Canada (2001); New York: Harcourt, 2001; Edinburgh: Canongate, 2002.

[2] Cole S. Believing in Tigers: Anthropomorphism and Incredulity in Yann Martel's Life of Pi. Studies in Canadian Literature, Vol. 2 (2004), p.22-36.

[3] Stratton F. Hollow at the core: Deconstructing Yann Martel's Life of Pi. Studies in Canadian Literature, Vol. 2 (2004), p.5-21.

[4] Wood J. Credulity. London Review of Books (2002), p.22-24.

[5] Cooper P. Life of Pi, by Yann Martel. Dictionary of Literary Biography (2006), p.326-341.

[6] Information on http://www.powells.com/fromtheauthor/martel.html.

[7] Sielke, S. “The Empathetic Imagination': An interview with Yann Martel”, Canadian Literature (2003), p.12-32.

[8] Empson W. Seven Types of Ambiguity. Los Angeles: New Directions Press(1947), p.1.

[9] Lacan J. Ecrits: A Selection, trans. Alan Sheridan, New York; Norton, see Donald Hall, Subjectivity, NY: Routledge, 2004.

[10] Yan-yu Zhang. Illusion or Reality, Mirror or Ego? --An Analysis of the Tiger Character in Life of $\mathrm{Pi}, 2012$ 